\title{
Erratum to: Prognostic factors of metastatic renal cell carcinoma with extensive sarcomatoid component
}

\author{
Inkeun Park • Yong Mee Cho $\cdot$ Jae-Lyun Lee $\cdot$ Jin-Hee Ahn $\cdot$ Dae-Ho Lee $\cdot$ \\ Cheryn Song $\cdot$ Jun-Hyuk Hong $\cdot$ Choung-Soo Kim $\cdot$ Hanjong Ahn
}

Published online: 10 August 2013

(c) Springer-Verlag Berlin Heidelberg 2013

Erratum to: J Cancer Res Clin Oncol (2013)

139:817-827

DOI 10.1007/s00432-013-1386-4

Unfortunately, in the original version of this article contained error. The authors would like to correct the misinformed study in the published article.

On p. 826, in Table 5, 1st row referring Staehler et al.'s study, "sunitinib after failure to GD" should be "sorafenib after failure to GD." The amended Table 5 is provided on the next page.

The online version of the original article can be found under doi:10.1007/s00432-013-1386-4.

I. Park · J.-L. Lee $(\varangle) \cdot$ J.-H. Ahn · D.-H. Lee

Department of Oncology, Asan Medical Center, University of Ulsan College of Medicine, 88, Olympic-Ro 43-Gil,

Songpa-gu, Seoul 138-736, Korea

e-mail: jaelyun@amc.seoul.kr

I. Park

e-mail: ingni79@hanmail.net

J.-H. Ahn

e-mail: drjiny@amc.seoul.kr

D.-H. Lee

e-mail: leedaeho@amc.seou.kr

Y. M. Cho

Department of Pathology, Asan Medical Center, University

of Ulsan College of Medicine, Seoul, Korea

e-mail: yongcho@amc.seoul.kr
C. Song · J.-H. Hong $\cdot$ C.-S. Kim $\cdot$ H. Ahn

Department of Urology, Asan Medical Center, University of Ulsan College of Medicine, Seoul, Korea e-mail: cherynsong@amc.seoul.kr

J.-H. Hong

e-mail: jhhong@amc.seoul.kr

C.-S. Kim

e-mail: cskim@amc.seoul.kr

H. Ahn

e-mail: hjahn@amc.seoul.kr 


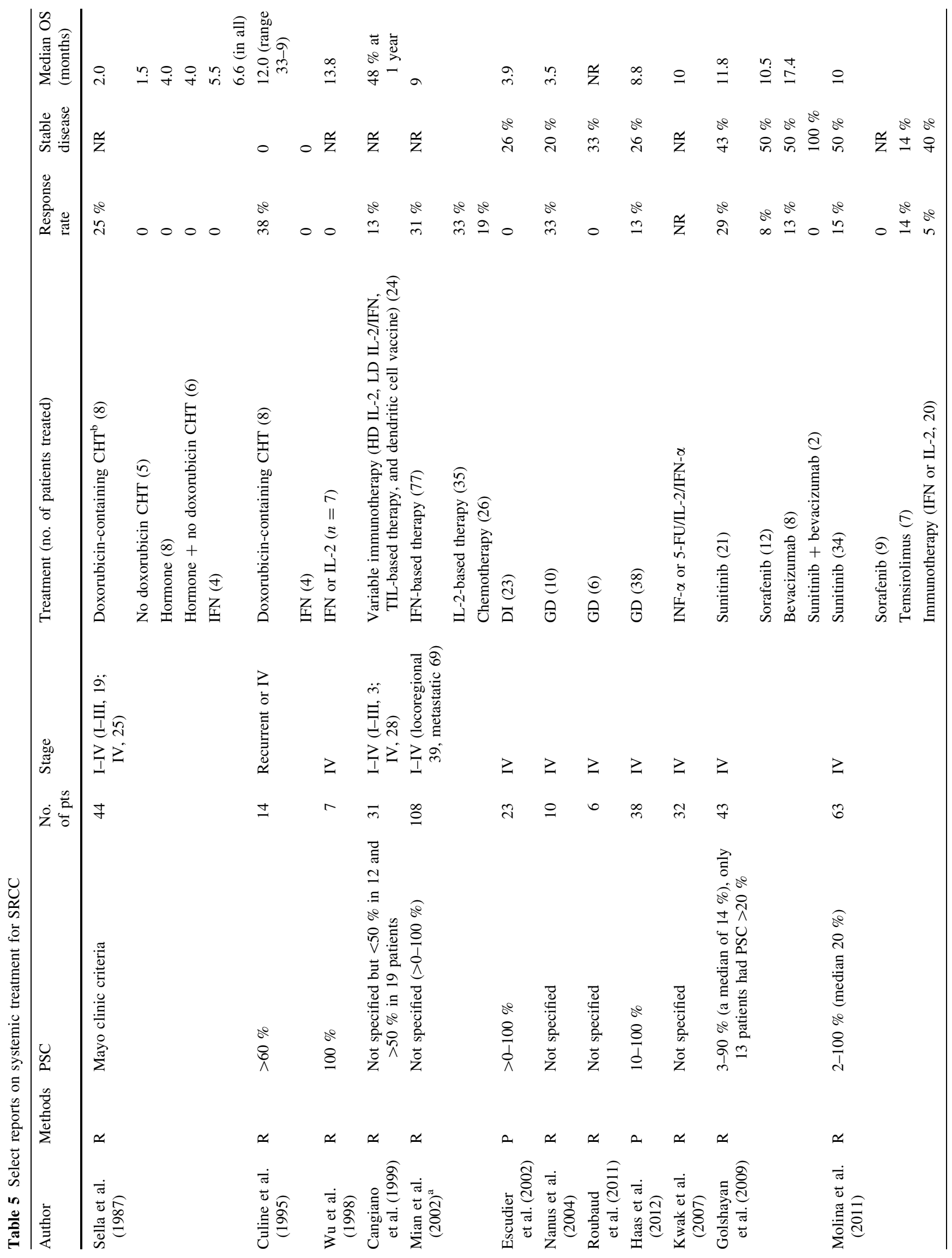


J Cancer Res Clin Oncol (2013) 139:1777-1779

1779

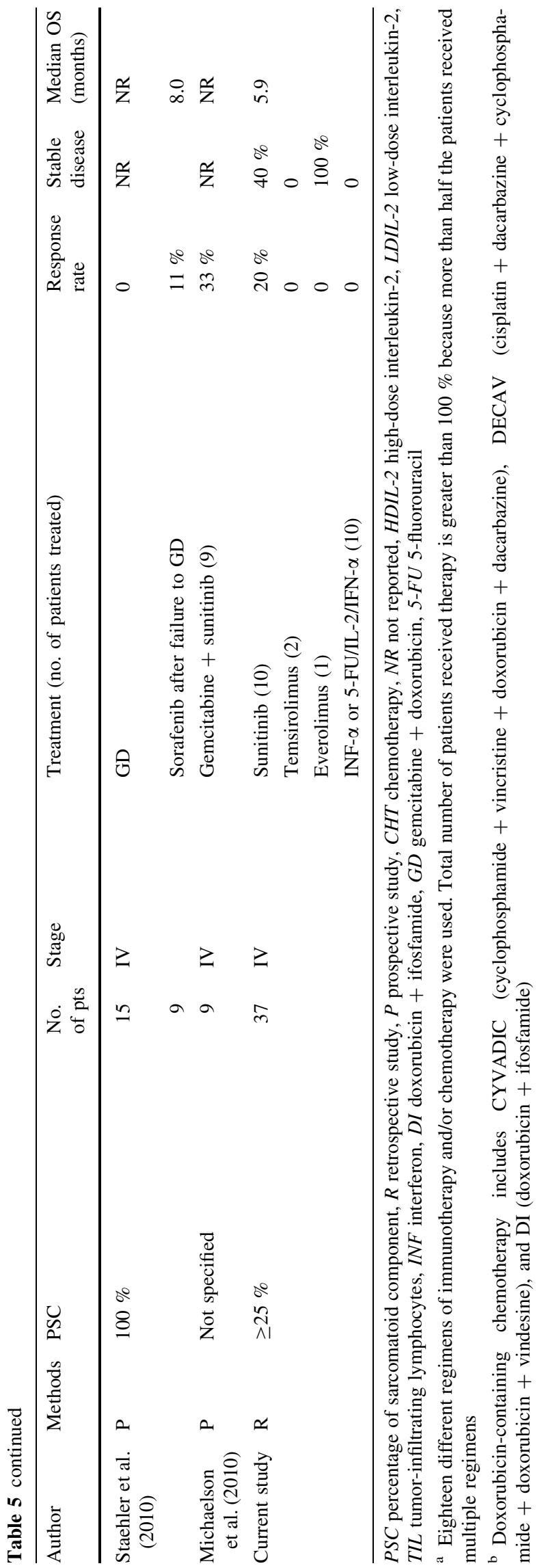

Springer 